\title{
Crosslinking and mass spectrometry suggest that the isolated NTD domain dimer of Moloney murine leukemia virus integrase adopts a parallel arrangement in solution
}

\author{
Daniel R Henriquez ${ }^{1}$, Caifeng Zhao ${ }^{2}$, Haiyan Zheng ${ }^{2}$, José J Arbildua ${ }^{3}$, Mónica L Acevedo ${ }^{1}$, Monica J Roth ${ }^{4}$ \\ and Oscar Leon ${ }^{1 *}$
}

\begin{abstract}
Background: Retroviral integrases (INs) catalyze the integration of viral DNA in the chromosomal DNA of the infected cell. This reaction requires the multimerization of $\mathrm{IN}$ to coordinate a nucleophilic attack of the $3^{\prime}$ ends of viral DNA at two staggered phosphodiester bonds on the recipient DNA. Several models indicate that a tetramer of IN would be required for two-end concerted integration. Complementation assays have shown that the N-terminal domain (NTD) of integrase is essential for concerted integration, contributing to the formation of a multimer through protein-protein interaction. The isolated NTD of Mo-MLV integrase behave as a dimer in solution however the structure of the dimer in solution is not known.

Results: In this work, crosslinking and mass spectrometry were used to identify regions involved in the dimerization of the isolated Mo-MLV NTD. The distances between the crosslinked lysines within the monomer are in agreement with the structure of the NTD monomer found in 3NNQ. The intermolecular crosslinked peptides corresponding to Lys 20-Lys 31, Lys 24-Lys 24 and Lys 68-Lys 88 were identified. The 3D coordinates of 3NNQ were used to derive a theoretical structure of the NTD dimer with the suite 3D-Dock, based on shape and electrostatics complementarity, and filtered with the distance restraints determined in the crosslinking experiments.

Conclusions: The crosslinking results are consistent with the monomeric structure of NTD in 3NNQ, but for the dimer, in our model both polypeptides are oriented in parallel with each other and the contacting areas between the monomers would involve the interactions between helices 1 and helices 3 and 4 .
\end{abstract}

\section{Background}

Protein-protein interactions play a fundamental role on the assembly of multimeric complexes of IN to carry out two-end concerted DNA integration [1-3]. Retroviral integrase structures are organized in three domains, a central domain that contain the catalytic site (CCD), a $\mathrm{N}$-terminal domain (NTD) that binds zinc and a Cterminal domain (CTD) having a SH3 fold [4].

Biochemical and genetic studies have shown that the NTD of integrase (IN) is involved in protein-protein

\footnotetext{
*Correspondence: oleon@med.uchile.cl

'Programa de Virologia ICBM, Facultad de Medicina, Universidad de Chile, Independencia 1027, Santiago, Chile

Full list of author information is available at the end of the article
}

interactions favoring protein multimerization and stabilization of the DNA-IN complex [5-8]. Prototype foamy virus (PFV) structure shows binding of this domain to LTR [9]. A polypeptide containing the first 105 amino acids of Mo-MLV IN, expressed in E. coli, is functionally active since it complements in trans an IN mutant lacking the NTD. Gel filtration chromatography indicates that this NTD behaves as a dimer in solution [8]. Similar observations have been made in HIV-1 IN [6]. The 3D structure of HIV-1 IN NTD, solved by NMR showed the dimer interface is highly hydrophobic and it includes the $\alpha$-helices 3 and 4 , and the N-terminal of helix 1 [10].

The NTD is essential for 3' processing and strand transfer, however determining its role in the integration

\section{Biomed Central}


process in lentiviruses and oncogenic viruses has been difficult due to the absence of the full-length structure of IN and the complexity of the protein-protein and protein-DNA interactions involved in the synaptic complex. Several models based on the partial 3D structure of IN fragments have been proposed for HIV-1 IN and ASV [11-13]. The X-ray structure of a tetrameric integrase complex of the PFV IN and processed U5 DNA was solved [14-16]. In this complex, the NTDs of the external subunits have been located at distal positions of the complex [17], however their structure was unresolved in the crystal structure. The quaternary structure of HIV integrase in solution has been examined by small and wide X-ray angle scattering and chemical crosslinking [18]. It has been concluded that integrase can assemble as a tetramer by the interaction of two different dimers: one of them is stabilized by interactions between the CCDs of two subunits while the other dimer is stabilized by interactions of one NTD with the CCD, CTD, and NTD of the other subunit. The interaction between the NTDs in the latter dimer was detected by chemical crosslinking [18].

A sequence alignment of the NTD of Mo-MLV, PFV and HIV-1 integrases is presented in Figure 1. The NTD of Mo-MLV IN is 45 amino acids larger than the NTD of HIV-1 IN [8]. PFV IN also contains an extra region of 50 amino acids before the zinc binding domain. Since no quaternary structural information for Mo-MLV IN is available, in this work we explored the use of crosslinking in order to identify lysine residues that are within the range of the cross-linking spacer within the monomer or the dimer on the NTD. Cross-linked peptides were identified and sequenced by MALDI-TOF MS/MS spectroscopy. Based on these results and the 3D coordinates available in $3 \mathrm{NNQ}$, a model of the NTD dimer was built. This model suggests a parallel arrangement of the NTDs.

\section{Results and discussion}

The NTD of Mo-MLV integrase behaves as a dimer in solution according to gel filtration on Superose 12 and favors multimerization of IN [6,8]. In complementation studies it has been shown that addition of an isolated NTD domain to an IN construct lacking this domain restores the activities of IN. However, there is no information on the structure of the dimer of Mo-MLV in solution and how it interacts with the other IN domains. In this work we carried out chemical crosslinking to identify lysine residues that were located on the interface of the dimer in order to determine the regions involved in dimerization. This procedure involved the analysis of the crosslinked peptides on the isolated dimer and uncrosslinked monomers by mass spectrometry [19-21].

\section{Chemical cross-linking of IN 1-105 with BS ${ }^{3}$}

Wild type IN 1-105 and K104C IN 1-105 were expressed in E. coli and purified by chromatography on Ni-NTA agarose. The proteins were 95\% pure as judged by SDS-PAGE (result not shown). Wild type IN 1-105 was crosslinked with bis[sulfosuccinimidyl] suberate $\left(\mathrm{BS}^{3}\right)$ in $50 \mathrm{mM}$ Hepes $\mathrm{pH} 7.8$ at $25^{\circ} \mathrm{C}$. Figure $2 \mathrm{~A}$ shows the results of the reaction kinetics using $56 \mu \mathrm{M}$ of IN 1105 and $100 \mu \mathrm{M} \mathrm{BS}{ }^{3}$. A protein band migrating near $29 \mathrm{kDa}$ corresponds to the expected dimer. In order to determine the effect of $\mathrm{BS}^{3}$ on IN 1-105 crosslinking, $\mathrm{BS}^{3}$ (between 0 and $300 \mu \mathrm{M}$ ) was used. The reactions were carried out at $25^{\circ} \mathrm{C}$ for $35 \mathrm{~min}$ and the results are shown in Figure 2B. Above $200 \mu \mathrm{M}$ of $\mathrm{BS}^{3}$, other high molecular weight products besides the dimer are observed. $100 \mu \mathrm{M} \mathrm{BS}{ }^{3}$ was used for crosslinking in the following experiments. Under these conditions approximately $50 \%$ of the protein was crosslinked.

In order to determine the size of the crosslinked protein complex, the crosslinking mixture was analyzed by gel filtration on Superdex S-200 under nondenaturing conditions. The elution profiles of crosslinked and unmodified IN 1-105 were almost identical (Figure 3), and the majority of the crosslinked IN 1-105 ( 95\%) elutes at the same position of the unmodified dimer. This result indicates that, under the conditions of the reaction, intermolecular crosslinking occurs within each dimer and rules out crosslinking between the dimers.

\section{Identification of intramolecular and intermolecular crosslinking peptide with $\mathrm{BS}^{3}$}

Chemical crosslinking combined with mass spectrometry (MS) provides a useful method for inferring sites of protein-protein interactions and for mapping the topology 


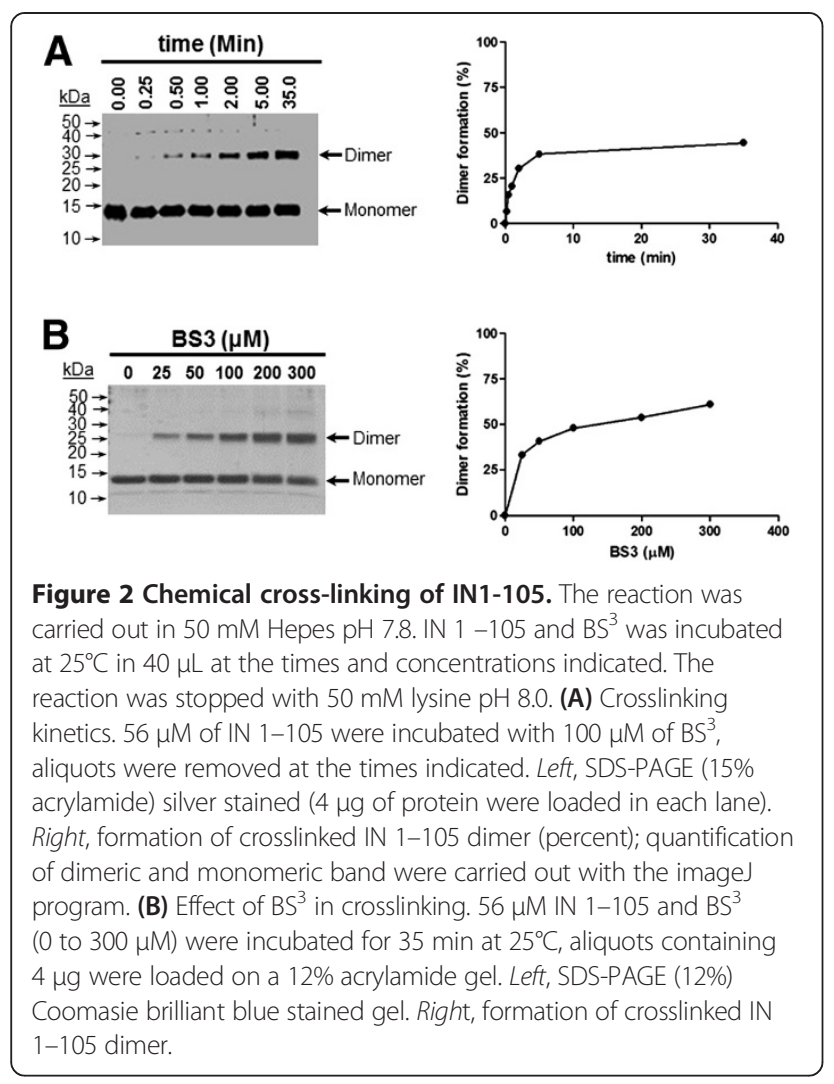

of protein complexes. We used the bi-functional crosslinking reagent $\mathrm{BS}^{3}$ that reacts with primary amine groups of lysines and the NTD integrase of Mo-MLV. In these experiments IN 1-105 was crosslinked with $\mathrm{BS}^{3}$ and the dimeric and monomeric band was separated by SDSPAGE, subjected to digestion with trypsin or chymotrypsin and analyzed by LC-MS/MS as indicated in Materials and Methods, being compared with the MS/MS profile of the unmodified IN 1-105, sequencing only differential peaks (Tables 1 and 2). In these cases only two informative sequences were used and classified as (1) intramolecular crosslinked peptides (or looplinks) and (2) intermolecular crosslinked peptides. Information about intramolecular crosslinking was obtained from reaction products in which both functional groups of the crosslinker reacted with lysine residues that reside in the same polypeptide chain (see Figures 4 and 5, Table 1). These peptides were sequenced by MS/MS and corresponded to the intramolecular crosslinking of: (1) residues K88 and K95 in (TLK ${ }^{88}$ NITETCK $^{95}$ ACAQVNASKS), (2) residues K31 and K33 in LGAYDK ${ }^{31} \mathrm{TK}^{33} \mathrm{~K}$, (3) residues K95 and K104 in NITETCK $^{95} \mathrm{ACAQVNASK}^{104} \mathrm{~S}$, (4) and residues K88 and K104 in TLK $^{88}$ NITETCKACAQVNASK $^{104}$ S. The informative contact position of lysines identified with the looplinks (see Table 1), was used to analyze the 3D crystal structure of the NTD of Mo-MLV integrase (3NNQ) in PDB data bank. We used this structure as a template and examined the distances between the crosslinked lysines. A

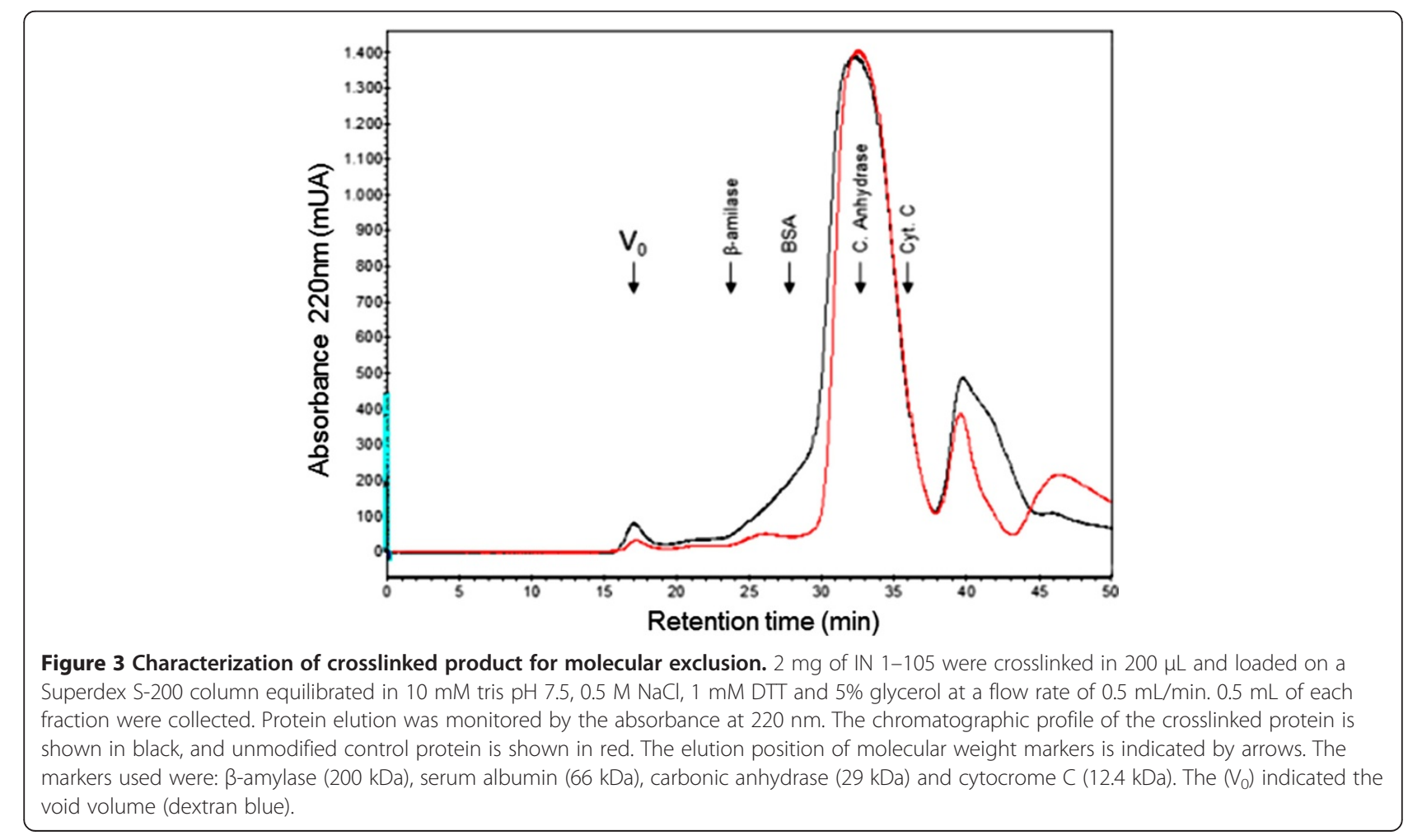


Table 1 Looplinked peptides sequences of BS $^{3}$ crosslinked peptides of Mo-MLV IN NTD and the C $\beta$ distances between modified lysine residues in the generated model

\begin{tabular}{|c|c|c|c|}
\hline Crosslinking & $\begin{array}{l}\text { Peptide } 1 \\
\end{array}$ & Lysine involved & Distance $(\AA)$ \\
\hline \multirow[t]{4}{*}{ Looplinks } & TLK $^{88}$ NITETCK $^{95}$ ACAQVNASKS & $88-95$ & 15.45 \\
\hline & LGAYDK $^{31} \mathrm{TK}^{33} \mathrm{~K}$ & $31-33$ & 7.32 \\
\hline & NITETCK ${ }^{95}$ ACAQVNASK ${ }^{104} \mathrm{~S}$ & $95-104$ & 16.15 \\
\hline & TLK ${ }^{88}$ NITETCK - ACAQVNASK ${ }^{104} \mathrm{~S}$ & $88-104$ & 20.74 \\
\hline
\end{tabular}

The distances were defined using SwissPdbViewer program.

maximum limit for productive crosslinking of $21.3 \AA$ has been used as a restraint for the distance between the $C \beta$ of two crosslinked lysines using $\mathrm{BS}^{3}$ [22]. The distances between the crosslinked lysines were within the $21.3 \AA$ limit, although the crosslinked K88-K104 was near this limit. Thus, our results are in agreement with the monomeric structure of the NTD domain in 3NNQ (Table 1).

The next step was to determine the contact zones of the dimeric protein-protein interface, using the information of the reaction products in which the crosslinked functional groups belonged to different polypeptides (see Table 2). Figure 6 shows the profile of one of these differential peptides obtained after digestion of the dimeric band with chymotrypsin. The peptide was sequenced yielding the sequence TVTDIKDLTK ${ }^{24}$ LGAIY - $\mathrm{TK}^{24} \mathrm{~L}$, which contain the crosslinked residues K24 and K24 suggesting the proximity between both $\mathrm{N}$-terminal ends of the polypeptides. When a similar analysis of the crosslinked protein was carried out using trypsin, a large peptide $(\mathrm{m} / \mathrm{z}$ nearly 5,000$)$ was observed (Figure $7 \mathrm{~A})$ that would correspond to crosslinking between K31 and either K20 or K24 indicated for the mass of the fragment (bioworks software analysis) of $4999.5366 \mathrm{~m} / \mathrm{z}$. This peptide could not be sequenced by MS/MS due to its large size. However when the crosslinked IN 1-105 dimer was digested with chymotrypsin, a peptide corresponding to crosslinking of residues $\mathrm{K} 20$ and $\mathrm{K} 31$ on each of the polypeptide chains was identified and sequenced (Figure 7B). These results indicate that crosslinking occurs between $\mathrm{K} 20$ and K31 of different polypeptides. A third crosslinked peptide was identified after tryptic digestion of the crosslinked dimer in the MS/MS sequences as $\mathrm{MK}^{68}$ ALLER-TLK ${ }^{88}$ NITETCK indicating that K68 and K88 are crosslinked (Figure 8). The intermolecular crosslinking pattern identified shows a particular distribution along the NTD (see Table 2). These results allow us to produce a $3 \mathrm{D}$ model and characterize the dimeric interface.

\section{Model of the NTD dimer of Mo-MLV integrase}

3D-dock suite was used to generate 10,000 possible complexes through the rotation and translation of a mobile monomer (3NNQ), around the fixed coordinates of another 3 NNQ monomer. This set of possible dimers was filtered using the experimental crosslinking information, to select the complex that agrees with the distance restraint data. A distance of $21.3 \AA$ between crosslinked lysines was used to select complex candidates. The selected dimers were submitted to an energy minimization protocol in order to optimize steric and electrostatic interactions of the residues involved in the protein protein interface. All the dimeric structures that satisfied the distance restraints showed a parallel disposition, with the residues involved in the crosslinking distributed in the same longitudinal face of the protein and both polypeptide chains arranged in the same direction. The complex with the more stable interface, according to Multidock routine of 3D-dock suite, was chosen as the more probable NTD - NTD dimer. A ribbon representation of the selected model is presented in Figure 9, showing the lysine residues that were crosslinked. This model shows a symmetric and parallel orientation of the monomers and two points of contact. (1) In the first $\alpha$-helix of the N-terminal domain (between K24-K24) and (2) the fourth $\alpha$-helix of chain A (blue) with the fourth $\alpha$-helix of chain B (brown) of the dimer. This

Table 2 Intermolecular peptides sequences of BS $^{3}$ crosslinked peptides of Mo-MLV IN NTD and the C $\beta$ distances between modified lysine residues (bold type) in the dimeric model

\begin{tabular}{|c|c|c|c|c|}
\hline Crosslinking & Peptide 1 & Peptide 2 & Lysine involved & Distance $(\AA)$ \\
\hline \multirow[t]{4}{*}{ Intermolecular crosslinking } & TVTDIKDLTK ${ }^{24}$ LGAIY & $T K^{24} \mathrm{~L}$ & $24-24 *$ & 15.14 \\
\hline & LGAYDK ${ }^{31} T K$ & MIENSSPYTSEHFHYTVTDIK ${ }^{20}$ DLTK ${ }^{24}$ LGAIYDK & $31-20 / 24$ & 20.02 \\
\hline & $\mathrm{DK}^{31} \mathrm{TKKY}$ & TVTDIK ${ }^{20} D L T K L$ & $31-20 *$ & 20.02 \\
\hline & $M K^{68}$ ALLER & TLK ${ }^{88}$ NITETCK & $68-88$ & 13.57 \\
\hline
\end{tabular}

()* Peptides obtained by chymotrypsin digest.

The distances were defined using SwissPdbViewer program. 


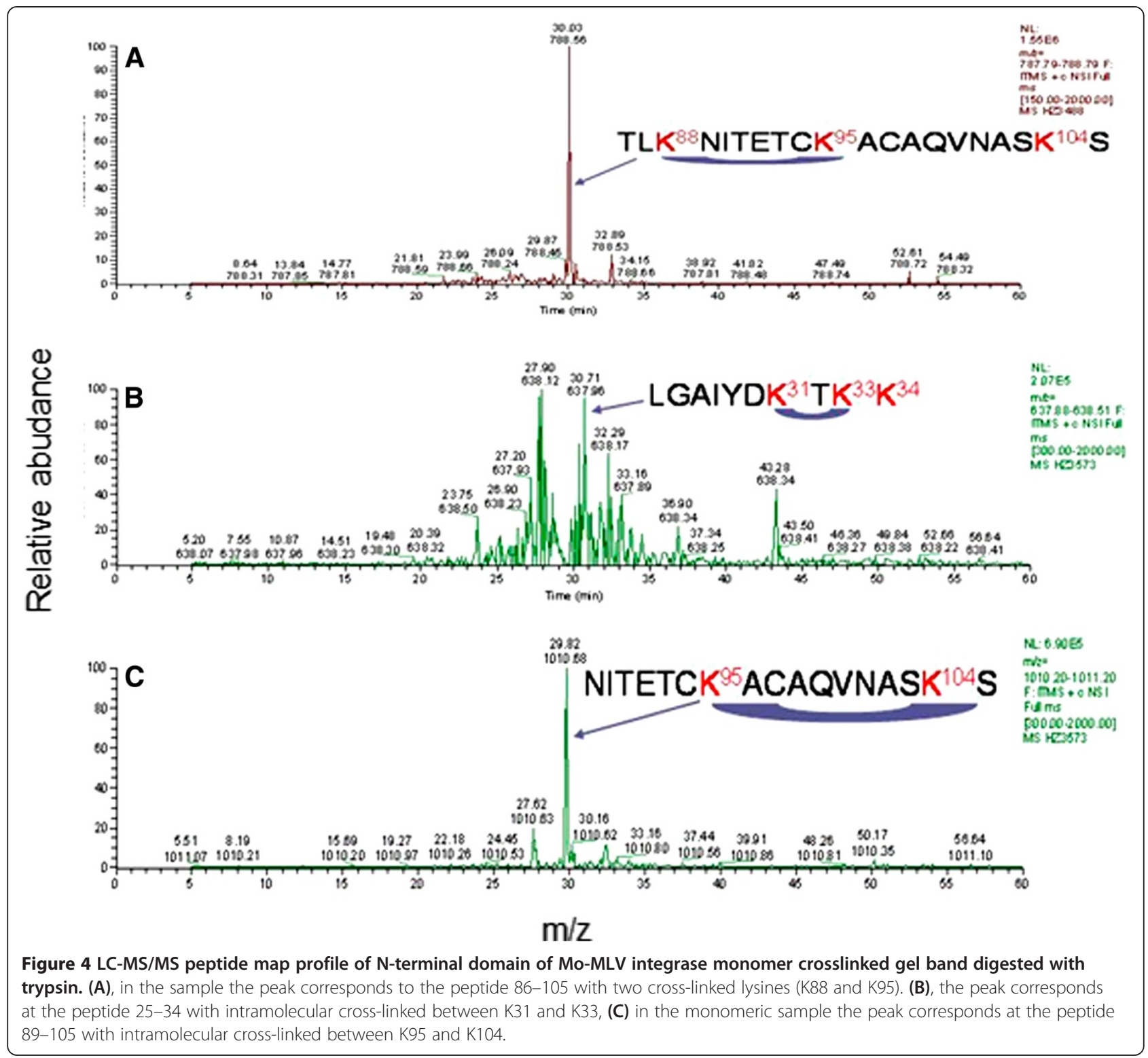

parallel arrangement would be mainly stabilized by electrostatic and Van der Waals interactions, where residues: L 25, D 84, R 85 and D 92 of monomer A and $\mathrm{K} 24, \mathrm{~L} 25, \mathrm{D} 84$ and D 92 of monomer B, play the main role in complex stabilization. The complex is characterized for a $\triangle \mathrm{ASA}$ of $484 \AA^{2}$, involving 16 residues of the first monomer and 17 residues of the second monomer. The gain in $\Delta G$ of solvation from the protein-protein interaction was estimated by PDBePISA server in $2.5 \mathrm{Kcal} / \mathrm{Mol}$ (http://www.ebi.ac. uk/msd-srv/prot_int/cgi-bin/piserver).

The solution structure of the isolated HIV-1 NTD dimer also exhibits a parallel arrangement [10], however, structural information on isolated NTDs of other integrases is not available.
It is generally thought that a tetramer is involved in the integration process. It has been proposed that this tetramer is assembled by two dimers that differ in their conformation. Differences in conformation reflect different combinations of interactions between the three domains of the enzyme. Crosslinking experiments in solution have revealed NTD-NTD interactions in the tetramer [18] that were not observed in the crystal structure of fragments of HIV-1 IN or PFV IN structure. It has been speculated that this kind of interaction may be related to a "domain swapping" phenomenon in which an interaction between the NTD and CCD domains is substituted by an interaction between the NTDs [18]. It is possible that this interaction may be evident in the isolated NTDs due to the absence of the CCD domain. 


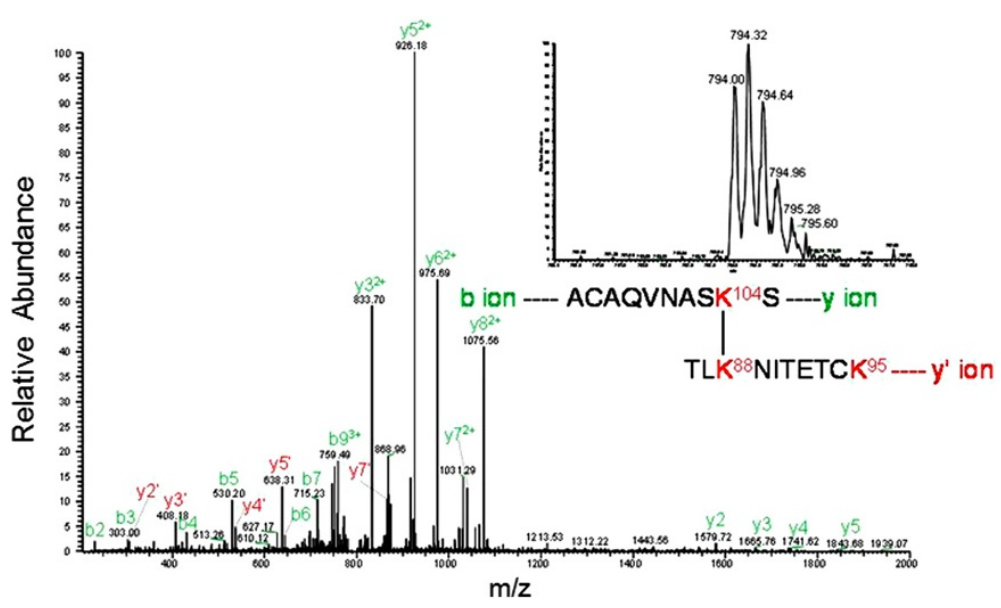

Figure 5 LC-MS/MS peptide map profile of N-terminal domain of Mo-MLV integrase monomer crosslinked gel band. Samples were digested overnight at $37^{\circ} \mathrm{C}$ with $0.8 \mathrm{\mu g}$ of trypsin. The image shows the ionization and sequence of the LC peak (indicated in the inset) corresponding at the intramolecular peptide 96-105 and 86-95 with K88 and K104 modified.

\section{Cysteine crosslinking}

In order to test our model, we performed crosslinking studies introducing cysteine residues at position 104 in IN1-105 (K104C). This amino acid residue was chosen because the $\mathrm{C} \alpha$ of both $\mathrm{K} 104$ in the $3 \mathrm{NNQ}$ dimer is separated by $28 \AA$. In contrast, the distance between these residues in our model is only $10 \AA$. Therefore crosslinking with BMOE (8 $\AA$ ) would be distinguished between both models. The mutant K104C IN1-105 was obtained by site directed mutagenesis and purified as described in Materials and Methods. This protein was able to complement a concerted integration assay that used a deletion mutant IN lacking the NTD domain (Figure 10). In addition, IN 1-105 contains two cysteine residues (C94 and 96) coordinated with zinc, that are not reactive to N-ethylmaleimide [8]. K104C IN 1-105

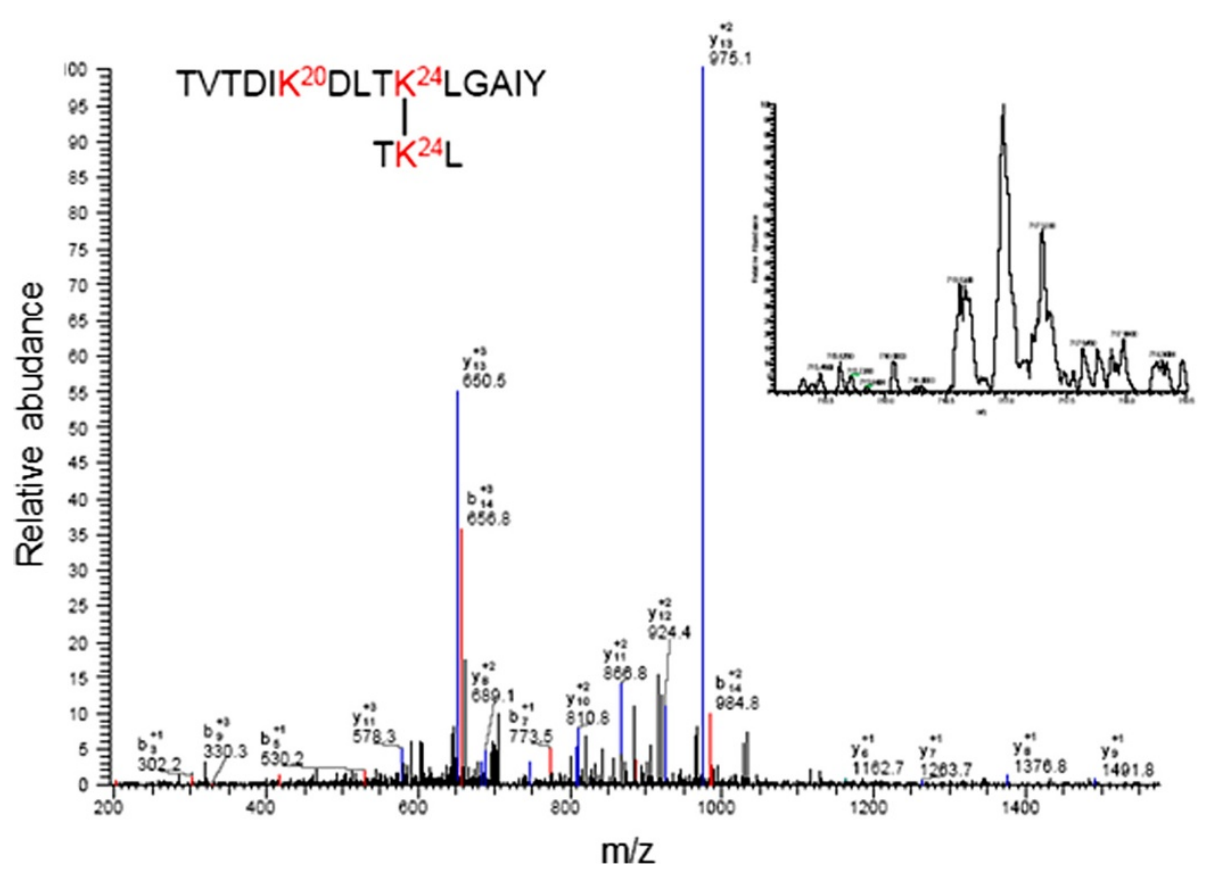

Figure 6 LC-MS/MS profile of N-terminal domain of Mo-MLV integrase cross-linked with BS $^{3}$. Samples in solution were digested overnight at $37^{\circ} \mathrm{C}$ with chymotrypsin in a ratio of 1:20 wt/wt (enzyme: protein). The image shows the ionization and sequence of the LC peak (indicated with asterisk in the inset) corresponding at the intermolecular peptide 15-29 and 23-25 with K24 and K24 crosslinked. 

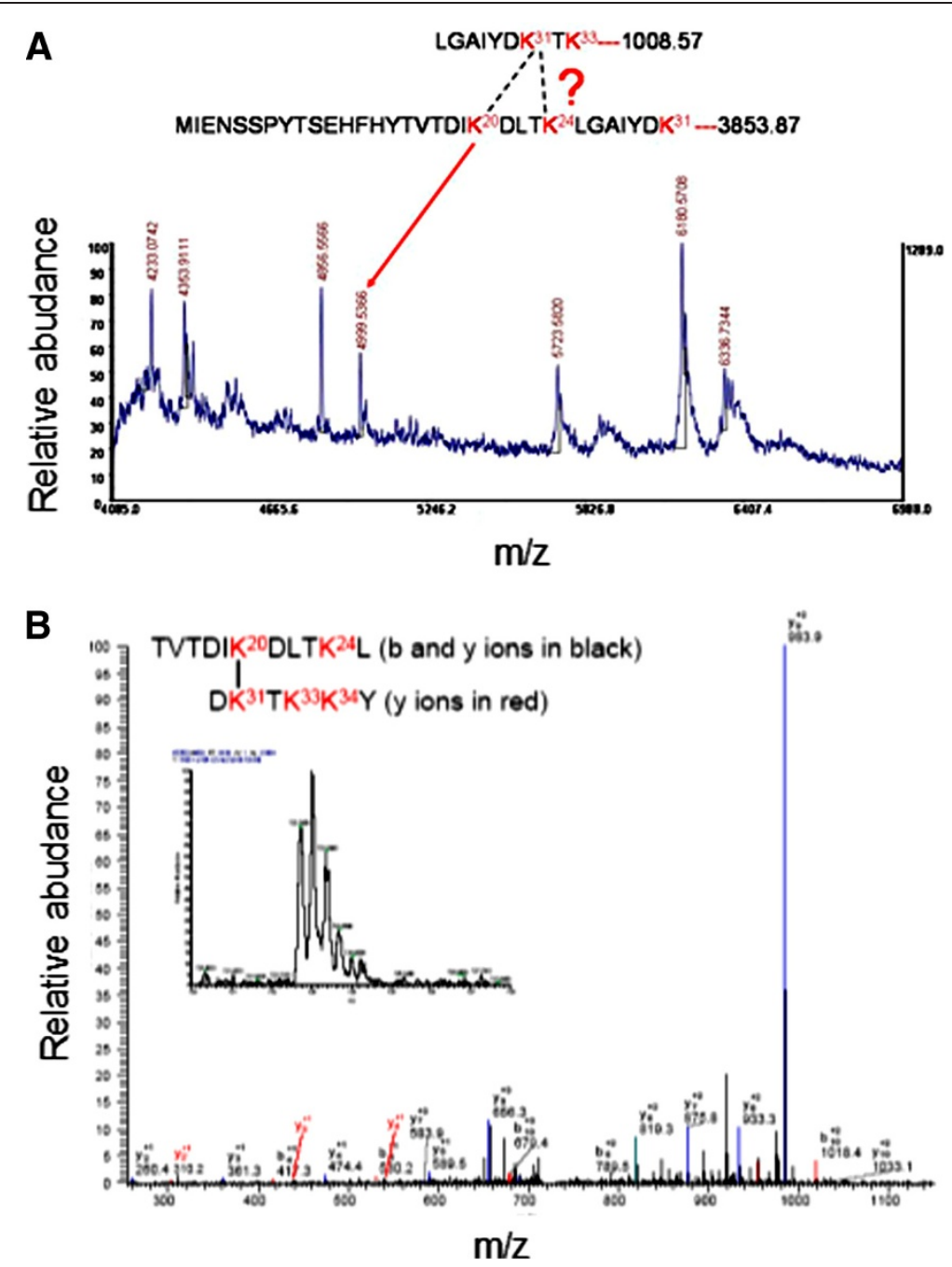

Figure 7 Intramolecular crosslinking peptide. (A) MALDI-TOF profile of the tryptic digest of dimeric band of IN 1-105 crosslinked with BS ${ }^{3}$. Samples were digested overnight at $37^{\circ} \mathrm{C}$ with trypsin in a ratio of 1:20 wt/wt (enzyme: protein). The image showed the peak $4999.5366(\mathrm{~m} / \mathrm{z})$ corresponding at the intermolecular peptide 25-33 and 1-31 with K31 and K20 or K24 modified. (B) LC-MS/MS profile of the chymotryptic IN 1-105 were cross-linked with $\mathrm{BS}^{3}$. Samples were digested overnight at $37^{\circ} \mathrm{C}$ with chymotrypsin in a ratio of 1:20 wt/wt (enzyme:protein). The image shows the ionization and sequence of the LC peak (indicated in the inset) corresponding at the intermolecular peptide 15-25 and 30-35 with K31 and K20 crosslinked.

protein was crosslinked with $\mathrm{BMOE}$ and $\mathrm{BM}(\mathrm{PEG})_{2}$ of 8 and $14.7 \AA$ in length, respectively. Figure 11 shows that both reagents produced crosslinked dimer of K104C IN 1-105 (lanes 2 and 3) indicating that the SH groups of cysteines are within $8 \AA$. The estimated crosslinking extent was $65 \%$ for $\mathrm{BMOE}$ and $70 \%$ for $\mathrm{BM}(\mathrm{PEG})_{2}$. The distance between the cysteines in the 3D coordinates of 3NNQ dimer would be more than $28 \AA$. Furthermore in 3 NNQ both carboxyl ends are separated by interactions with helix 3 of the other monomer reducing the flexibility of the polypeptide chain at the position of K104.

In order to confirm that crosslinking was not produced by the reaction between dimers due to the high reactivity of BMOE with $\mathrm{SH}$ groups, the crosslinked reaction mixture was further analyzed by gel filtration on superdex S-200. After crosslinking with BMOE most of the protein eluted as a dimer (not shown).

\section{Conclusions}

All retroviral integrases contain a HHCC zinc finger motif at the $\mathrm{N}$-terminal domain that is involved in protein-protein interactions, which is essential for retroviral integration. The structure of NTD of HIV-1 IN has been solved by X-ray crystallography and NMR. However for Mo-MLV with a larger NTD domain, the only information available is the deposited $\mathrm{x}$-ray structure 


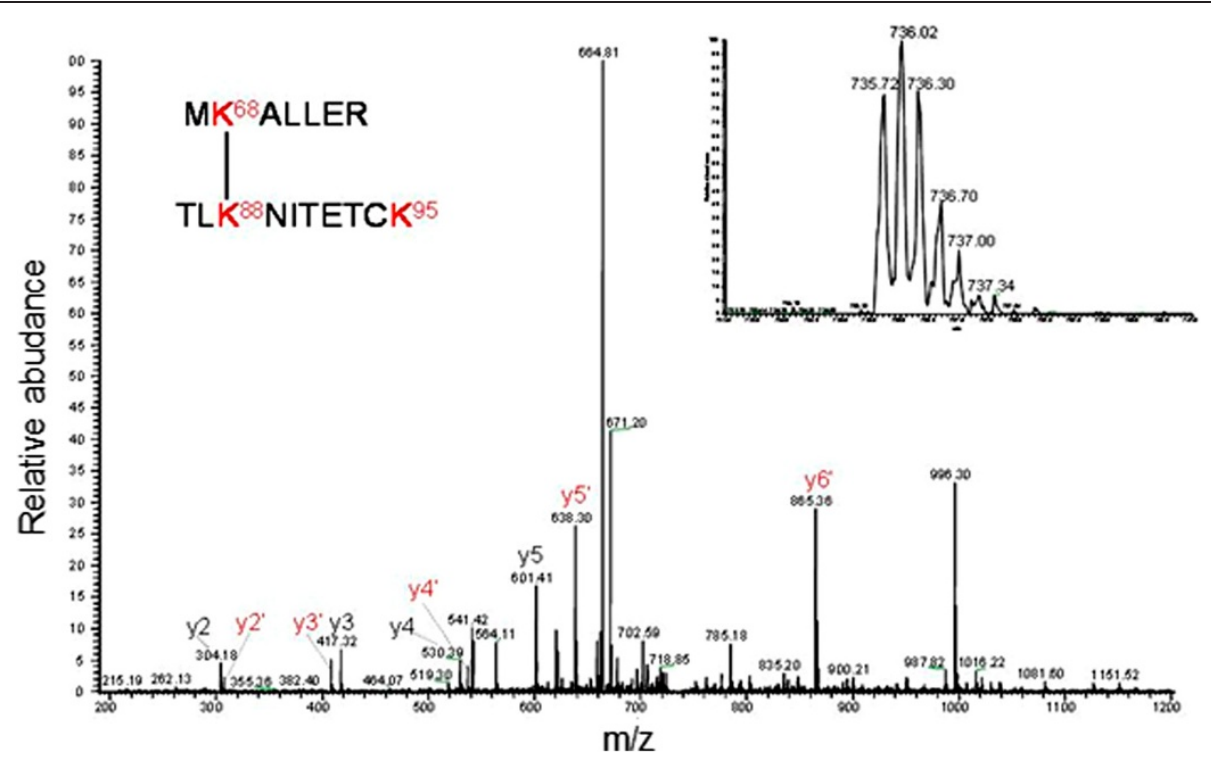

Figure 8 Intermolecular crosslinking. LC-MS/MS peptide map profile obtained of the dimer crosslinked gel band of N-terminal domain of Mo-MLV integrase. The dimer was digested with $0.8 \mu \mathrm{g}$ of trypsin at $37^{\circ} \mathrm{C}$ overnight. The image shows the ionization and sequence of the LC peak (indicated in the inset) corresponding at the intermolecular peptide 67-73 and 86-95 with K68 and K88 crosslinked with BS ${ }^{3}$.

3NNQ. The dimeric structure represented in the asymmetric unit of 3NNQ fails to explain our crosslinking results. Studies of the isolated Mo-MLV NTD indicates that the domain behaves as a dimer in solution and as such is active in complementation of the IN activities. Therefore our aim was to determine the contacting regions of the NTD domain using chemical crosslinking and mass spectrometry to identify the dimer present in solution. Identification of intramolecular crosslinks of lysines using $\mathrm{BS}^{3}$ as a spacer agree with the conformation of the monomer in 3NNQ. However, the intermolecular crosslinking results did not match the interacting regions found in 3NNQ dimer.

The current approach to determine protein-protein interaction in the NTD domain of Mo-MLV integrase includes the use of the 3D coordinates of the $3 \mathrm{NNQ}$ monomer and experimental distance restraints obtained using lysines crosslinking and MS/MS sequencing methodologies. We propose a homodimeric model where both polypeptides are aligned in parallel with the $\beta$ strands away from the interface, formed mainly by helices 1 and 4 .

Our model was tested by cysteine crosslinking with $\mathrm{BMOE}$ and as expected a high crosslinking yield was achieved. We expect that this theoretical model could be useful to test other properties of the NTD such as its interactions with the other domains of IN and to understand the mechanisms used by this HHCC domains to regulate protein interactions in different contexts.

\section{Methods}

\section{Integrase purification}

E. coli BL21 (DE3) harboring the plasmid pET/IN 1-105 was used to express IN 1-105 [8]. Protein production was induced with lactose according to the protocol of Studier, F. [23]. Cells were grown at $20^{\circ} \mathrm{C}$ up to 5 O.D. at $600 \mathrm{~nm}$ in $400 \mathrm{~mL}$. Cells were collected by centrifugation at $6,000 \mathrm{rpm}$ for $30 \mathrm{~min}$ in a Sorvall RC-5, GSA rotor. The pellet was resuspended in $40 \mathrm{~mL}$ of lysis buffer $(10 \mathrm{mM}$ CHAPS, $10 \mathrm{mM}$ imidazole, $300 \mathrm{mM} \mathrm{NaCl}$, $50 \mathrm{mM} \mathrm{NaH} \mathrm{PO}_{4} \mathrm{pH} 8,0$ and protease inhibitor tablet (Roche) was sonicated for 6 pulses of $30 \mathrm{~s}$ at maximum intensity (Branson) and the cell debris was removed by centrifugation at 9,000 rpm for $40 \mathrm{~min}$. $1 \mathrm{~mL}$ of Ni-NTA -agarose was added to the supernatant and mixed overnight by rotation in a twister VS- $96 \mathrm{TW}$ at $4{ }^{\circ} \mathrm{C}$. The resin was washed with $40 \mathrm{~mL}$ of buffer $1(50 \mathrm{mM}$ $\mathrm{NaH}_{2} \mathrm{PO}_{4}$ pH 8.0, $10 \mathrm{mM}$ CHAPS, $1 \mathrm{M} \mathrm{NaCl}$, $10 \mathrm{mM}$ 2-mercaptoethanol, 20\% glycerol for $10 \mathrm{~min}$ and the resin was set on a column (BioRad). The column was washed sequentially with $4 \mathrm{~mL}$ of: 25,50 , 100 and $250 \mathrm{mM}$ imidazole dissolved in buffer 1 . Fractions of $1 \mathrm{~mL}$ were collected. Protein was quantified by Bradford (BioRad) and analyzed by SDS-PAGE on $15 \%$ acrylamide gels.

\section{Construction of K104C IN 1-105 mutant}

This construct was made by PCR using the plasmid pET IN1-105 as a template [8] and the mutagenic primer K104C 5'-AAA AGG ATC CTA AGA GCA GCT GGC 


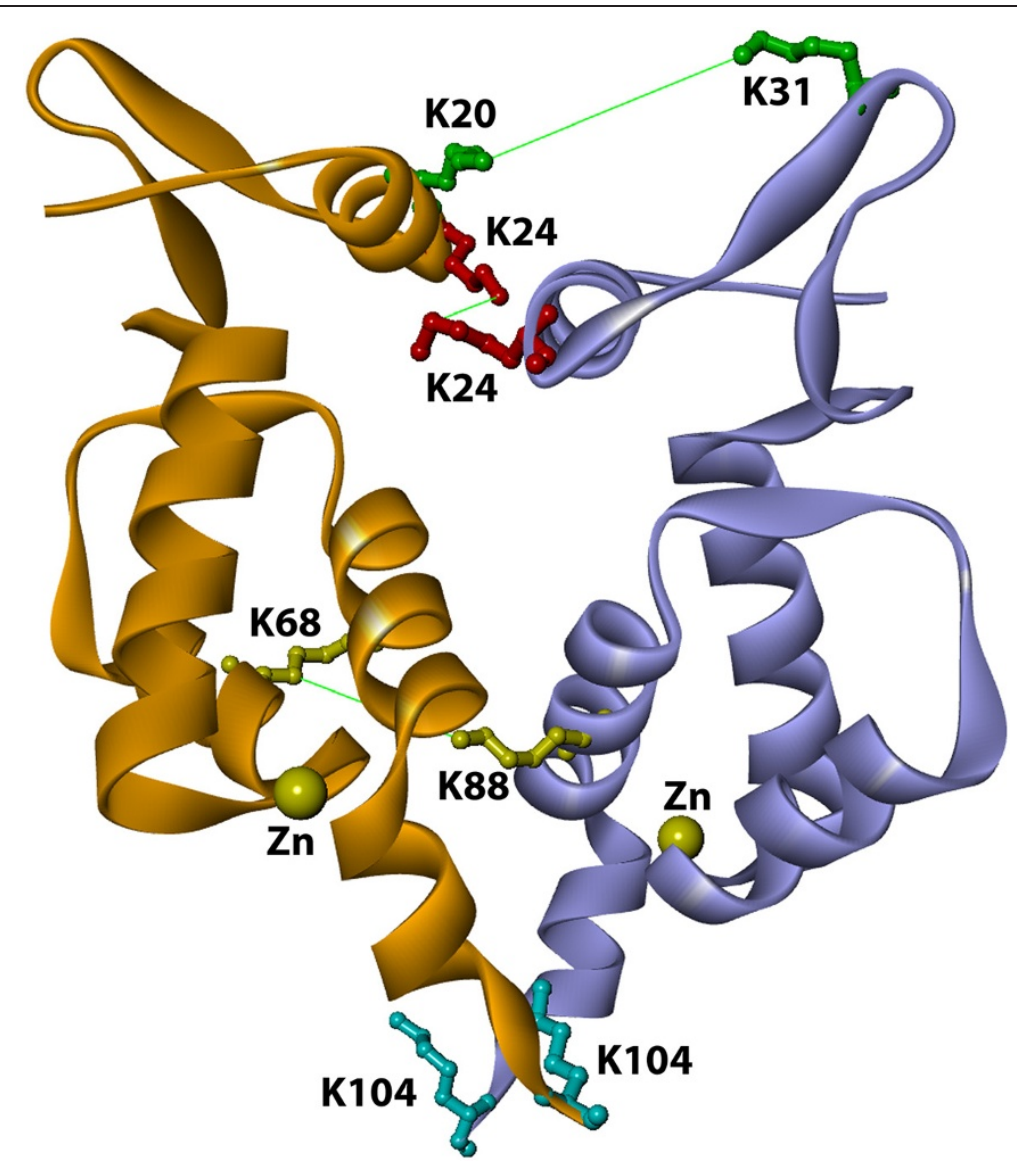

Figure 9 Modeling of dimer conformation of N-terminal domain of Mo-MLV integrase. Visualization of intermolecular crosslinking products with Swiss-PdbViewer of the dimeric interfase of NTD of Mo-MLV integrase (3NNQ pdb template, experimental crosslinking strain and 3D-Dock suite used for model). The amino acid involved in the crosslinking and its distances are indicated K31-K20 (green 20.02 $\AA$ ), K24-K24 (red $15.14 \AA$ ) and K88-K68 (yellow 13.57 A), all of them are in agreement with the spacer arm of BS 3 . K104 (light blue) and zinc atoms (yellow) are also indicated.

GTT GA -3' that included the BamHI site (underlined) and the T7 promoter 5'- CTATAGTGAGTCGTATTA -3'. The 480 bp PCR product was digested with NdeI and BamHI (NEB) and purified by electrophoresis in $1.2 \%$ agarose gels and ligated to pET $11 \mathrm{~b}$ digested with NdeI and BamHI. The mutation was confirmed by DNA sequencing.

\section{Chemical crosslinking of IN 1-105}

The experimental approach to identify crosslinked lysines is based on the use of homo- bifunctional crosslinking agents that are directed primarily towards amino groups. $\varepsilon-\mathrm{NH}_{2}$ groups of lysine or the $\alpha-\mathrm{NH}_{2}$ of the $\mathrm{N}$-terminal amino acid of the protein would potentially react with the $\mathrm{N}$-hydroxysuccinimide ester. This in turn produces intramolecular crosslinking when lysines of the same polypeptide are located at the appropriate distance. Intermolecular crosslinking can also be produced when the reactive lysines are located in different polypeptides. In our approach the reacted protein was digested with sequencing grade proteases and analyzed by MALDI TOF/TOF and LC-MS/MS to identify the position of crosslinking. For the first round analysis, the data was searched using Bioworks with +138 (for intra peptide link) and +156 as lysine variable modifications. In these studies the homobifuntional crosslinker bis(sulfosuccimidyl) suberate $\left(\mathrm{BS}^{3}\right.$, Pierce) was used. This crosslinker spans $11.4 \AA$. 0.4 nmoles of the IN $1-105(10 \mu \mathrm{M})$ was incubated at $25^{\circ} \mathrm{C}$ in $50 \mathrm{mM}$ Hepes $\mathrm{pH} 7.8$ and $100 \mathrm{mM} \mathrm{NaCl}$ with $100 \mu \mathrm{M}$ of $\mathrm{BS}^{3}$ for $35 \mathrm{~min}$. The crosslinking reaction mixture was quenched with a loading buffer of protein and $50 \mathrm{mM}$ lysine $\mathrm{pH} 8.0$ and subjected to SDS-PAGE and stained with Coomasie Brilliant Blue. Under these conditions 50\% of IN 1105 was crosslinked. The protein band corresponding to the crosslinked dimer was excised and digested with trypsin for mass spectrometry analysis.

\section{Characterization of crosslinked products of IN 1-105 by gel filtration}

$1.3 \mathrm{mg}$ of protein in $2 \mathrm{~mL}$ was crosslinked as described above. The reaction products were concentrated 10 -fold 

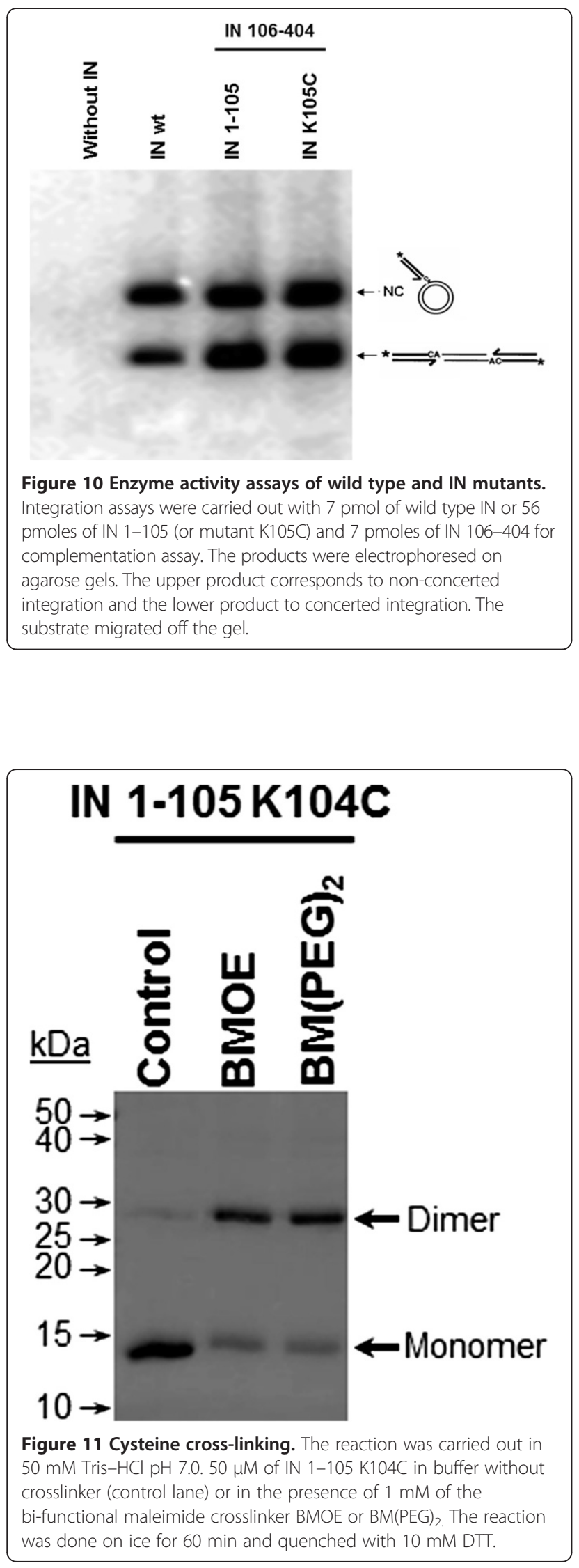

in an Amicon filter (10000 MWCO, Millipore) and $1.3 \mathrm{mg}$ of protein $(200 \mu \mathrm{L})$ was loaded on a Superdex S200 column $(30 \times 1.7 \mathrm{~cm}$ Pharmacia), equilibrated with $10 \mathrm{mM}$ Tris $\mathrm{HCl} \mathrm{pH}$ 7.5, $0.5 \mathrm{M} \mathrm{NaCl}, 1 \mathrm{mM}$ DTT and $5 \%$ glycerol which were connected to a diode array detector (Jasco). Fractions of $0.5 \mathrm{~mL}$ were collected and the protein visualized by SDS-PAGE $12 \%$ and Coomasie Brilliant Blue staining.

\section{Proteolytic digestion in gel}

The stained gel piece was incubated with $1 \mathrm{~mL}$ of $50 \mathrm{mM}$ of $\mathrm{NH}_{4} \mathrm{HCO}_{3}$ in $50 \% \mathrm{v} / \mathrm{v}$ acetonitrile for $1 \mathrm{~h}$ or until the stain disappeared. Then, the protein was reduced with $60 \mu \mathrm{L}$ of $20 \mathrm{mM}$ DTT in $50 \mathrm{mM} \mathrm{NH}_{4} \mathrm{HCO}_{3}$ for $15 \mathrm{~min}$ at $60^{\circ} \mathrm{C}$. The solution was removed and the gel was treated with $40 \mathrm{mM}$ iodoacetamide in $50 \mathrm{mM}$ $\mathrm{NH}_{4} \mathrm{HCO}_{3}$ for $30 \mathrm{~min}$ at $37^{\circ} \mathrm{C}$, in the dark. The gel piece was washed with $50 \mathrm{mM} \mathrm{NH} \mathrm{mCO}_{3}$ in $50 \% \mathrm{v} / \mathrm{v}$ acetonitrile and with $100 \%$ acetonitrile twice and dried $10 \mathrm{~min}$ at room temperature, then $0.8 \mu \mathrm{g}$ of trypsin in $40 \mu \mathrm{L}$ of $25 \mathrm{mM} \mathrm{NH} \mathrm{NCO}_{3}, \mathrm{pH} 7.8$ were added and incubated at $37^{\circ} \mathrm{C}$ for $16 \mathrm{~h}$. Peptides were recovered by concentration in speed vac and analyzed by LC-MS/MS (U3000 from Dionex and LTQ from Thermofisher) or MALDI-TOF/TOF (Applied biosystem).

\section{Proteolytic digestion in solution}

The crosslinking reaction mixture $(0.4$ nmoles of protein) in $50 \mathrm{mM} \mathrm{NH} \mathrm{NCO}_{3}$ was treated with $20 \mathrm{mM}$ iodoacetamide for $30 \mathrm{~min}$ at $37^{\circ} \mathrm{C}$. The reaction was stopped by the addition of $20 \mathrm{mM}$ DTT for $15 \mathrm{~min}$. Then, trypsin in a ratio 1:20 (wt/wt) was added, and the digestion was carried out at $37^{\circ} \mathrm{C}$ for $16 \mathrm{~h}$. The digested peptides were then analyzed by nano LC-MS/MS (U3000 from Dionex and LTQ from Thermofisher) or 4800 MALDI-TOF/TOF instrument (Applied biosystem).

\section{Peptide crosslinked analysis}

A list of likely peptides, containing one undigested lysine for trypsin or with more than one lysine for chymotrypsin, was used as lysine modification in order to compare with unmodified peptide profile of the control without $\mathrm{BS}^{3}$ and search LC-MS/MS data by Bioworks software or for manual interpretation of MALDI-MS/MS data. For intra-peptide cross-linking and $\mathrm{BS}^{3}$ single residue modification, 138.068 and 156.0786 were added on lysine as modifications respectively. The MS/MS spectra of cross-linked peptides were manually confirmed.

\section{Concerted two-end integration assay}

The concerted two-end integration assay is a modification of that previously described [24-26]. One pmole of the 5'labeled substrate used for strand transfer was incubated in SST buffer (20 mM MES pH 6,4, $20 \mathrm{mM} \mathrm{KCl,} \mathrm{5 \%} \mathrm{glycerol,}$ 
$10 \mathrm{mM}$ DTT, $20 \mathrm{mM} \mathrm{MnCl} 2$ and 10\% DMSO) for $30 \mathrm{~min}$ on ice with 7 pmol of IN wt or 56 pmoles of IN 1-105 (or mutant K105C) and 7 pmoles of IN 106-404 for complementation assay. Then 100 pmol of pUC18 DNA were added and incubated at $37^{\circ} \mathrm{C}$ for $1 \mathrm{~h}$ in a final volume of $15 \mu \mathrm{L}$. The reaction was stopped with $3 \mu \mathrm{L}$ of $0.1 \mathrm{M}$ EDTA, $5 \%$ SDS plus $1 \mu \mathrm{L}$ of proteinase $\mathrm{K}(20 \mathrm{mg} / \mathrm{mL})$ and incubated at $55^{\circ} \mathrm{C}$ for $1 \mathrm{~h}$. The reaction products were separated by electrophoresis on $1 \%$ agarose gels. The gel was dried and exposed on a Phosphor-Imager (Bio-Rad).

\section{Cysteine crosslinking}

Just prior to use, the IN 1-105 and K104C IN 1-105 were adjusted to $0.8 \mathrm{mg} / \mathrm{mL}$ and $\mathrm{ZnSO}_{4}(10 \mu \mathrm{M}$ final $)$ was added to chelate the cysteines of the zinc binding motif. The proteins were kept on ice for $30 \mathrm{~min}$. The bifunctional maleimide-coupled crosslinking agent $\mathrm{BMOE}$ (span arm $8 \AA$ ) and $\mathrm{BM}(\mathrm{PEG})_{2}$ (span arm $14.7 \AA$ ) were prepared in DMSO just prior to use. The crosslinker was added to the protein solution at a different crosslinker/ protein ratio. The reaction mixture was left on ice for $60 \mathrm{~min}$ and the crosslinker excess was quenched with $10 \mathrm{mM}$ DTT for $30 \mathrm{~min}$ with further $30 \mathrm{~min}$ on ice. The reaction products were analyzed by SDS-PAGE and protein were stained with Coomasie Brilliant Blue.

\section{Monomer of $\mathrm{N}$-terminal integrase}

Integrase $\mathrm{N}$-terminal 3D coordinates, residues 11 to 105 , was a modification of $3 \mathrm{NNQ}$ pdb file, where the three selenomethionine residues in Chain $\mathrm{A}$ were edited to methionine residues.

\section{Dimeric complex}

Integrase $\mathrm{N}$-terminal dimer was built using 3D-Dock suite and experimental crosslinking restraints. In summary, one monomer of $\mathrm{N}$-terminal integrase was defined to the program as a fixed structure and the other monomer as mobile. FTDock program, based on the correlation algorithm of Katchalski-Katzir plus an electrostatic function, generated 10,000 possible complexes through rotation and translation of the mobile monomer previous to the correlation calculations. Experimental cross linking information was used as a filter (filter routine in the suite) to select the complex that agreed with the distance restraint data [27]. After the model was selected, Multidock routine was used to refine the side chains of the amino acids involved in the interface and to perform a rigid body energy minimization of the complex.

\section{Competing interests}

The authors declare that they have no competing interests.

\section{Authors' contributions}

$\mathrm{DH}$ and MA performed the work, $\mathrm{HZ}$ and $\mathrm{CZ}$ carried out the mass spectrometry analysis and sequencing. JA carried out the modeling $\mathrm{OL}, \mathrm{MR}$ and $\mathrm{DH}$ conceived the study and coordinated the activities and writing. All authors read and approved the final manuscript and declare no conflict of interest.

\section{Author details}

${ }^{1}$ Programa de Virologia ICBM, Facultad de Medicina, Universidad de Chile, Independencia 1027, Santiago, Chile. ${ }^{2}$ Mass spectrometry facility at CABM, UMDNJ, New Jersey, USA. ${ }^{3}$ Present address: Facultad de Ingeniería y Ciencias, Universidad Adolfo Ibañez, Santiago, Chile. ${ }^{4}$ Department of Biochemistry, RWJMS-UMDNJ, Piscataway, New Jersey, USA.

Received: 7 January 2013 Accepted: 8 July 2013

Published: 11 July 2013

\section{References}

1. Lutzke RA, Plasterk RH: Structure-based mutational analysis of the Cterminal DNA-binding domain of human immunodeficiency virus type 1 integrase: critical residues for protein oligomerization and DNA binding. J Virol 1998, 72:4841-4848.

2. Li M, Mizuuchi M, Burke TR Jr, Craigie R: Retroviral DNA integration: reaction pathway and critical intermediates. EMBO J 2006, 25:1295-1304.

3. Jenkins TM, Engelman A, Ghirlando R, Craigie R: A soluble active mutant of HIV-1 integrase: involvement of both the core and carboxyl-terminal domains in multimerization. J Biol Chem 1996, 271:7712-7718.

4. Eijkelenboom AP, Lutzke RA, Boelens R, Plasterk RH, Kaptein R, Hard K: The DNA-binding domain of HIV-1 integrase has an SH3-like fold. Nat Struct Biol 1995, 2:807-810.

5. Ellison V, Brown PO: A stable complex between integrase and viral DNA ends mediates human immunodeficiency virus integration in vitro. Proc Natl Acad Sci U S A 1994, 91:7316-7320.

6. Zheng R, Jenkins TM, Craigie R: Zinc folds the N-terminal domain of HIV-1 integrase, promotes multimerization, and enhances catalytic activity. Proc Natl Acad Sci U S A 1996, 93:13659-13664.

7. Donzella GA, Leon O, Roth MJ: Implication of a central cysteine residue and the HHCC domain of Moloney murine leukemia virus integrase protein in functional multimerization. J Virol 1998, 72:1691-1698.

8. Yang F, Seamon JA, Roth MJ: Mutational analysis of the N-terminus of Moloney murine leukemia virus integrase. Virology 2001, 291:32-45.

9. Krishnan L, Li X, Naraharisetty HL, Hare S, Cherepanov P, Engelman A: Structure-based modeling of the functional HIV-1 intasome and its inhibition. Proc Natl Acad Sci U S A 2010, 107:15910-15915.

10. Cai M, Zheng R, Caffrey M, Craigie R, Clore GM, Gronenborn AM: Solution structure of the N-terminal zinc binding domain of HIV-1 integrase. Nat Struct Biol 1997, 4:567-577.

11. Podtelezhnikov AA, Gao K, Bushman FD, McCammon JA: Modeling HIV-1 integrase complexes based on their hydrodynamic properties. Biopolymers 2003, 68:110-120.

12. Chen A, Weber IT, Harrison RW, Leis J: Identification of amino acids in HIV-1 and avian sarcoma virus integrase subsites required for specific recognition of the long terminal repeat Ends. J Biol Chem 2006, 281:4173-4182.

13. Chen X, Tsiang M, Yu F, Hung M, Jones GS, Zeynalzadegan A, Qi X, Jin H, Kim CU, Swaminathan S, Chen JM: Modeling, analysis, and validation of a novel HIV integrase structure provide insights into the binding modes of potent integrase inhibitors. J Mol Biol 2008, 380:504-519.

14. Hare S, Gupta SS, Valkov E, Engelman A, Cherepanov P: Retroviral intasome assembly and inhibition of DNA strand transfer. Nature 2010, 464:232-236.

15. Hare S, Vos AM, Clayton RF, Thuring JW, Cummings MD, Cherepanov P: Molecular mechanisms of retroviral integrase inhibition and the evolution of viral resistance. Proc Natl Acad Sci U S A 2010, 107:20057-20062.

16. Hare S, Maertens GN, Cherepanov P: 3'-processing and strand transfer catalysed by retroviral integrase in crystallo. EMBO J 2012, 31:3020-3028.

17. Gupta K, Curtis JE, Krueger S, Hwang Y, Cherepanov P, Bushman FD, Van Duyne GD: Solution conformations of prototype foamy virus integrase and its stable synaptic complex with u5 viral DNA. Structure 2012, 20:1918-1928.

18. Bojja RS, Andrake MD, Merkel G, Weigand S, Dunbrack RL Jr, Skalka AM: Architecture and assembly of HIV integrase multimers in the absence of DNA substrates. J Biol Chem 2013, 288:7373-7386. 
19. Young MM, Tang N, Hempel JC, Oshiro CM, Taylor EW, Kuntz ID, Gibson BW, Dollinger G: High throughput protein fold identification by using experimental constraints derived from intramolecular cross-links and mass spectrometry. Proc Natl Acad Sci U S A 2000, 97:5802-5806.

20. Livney YD, Schwan AL, Dalgleish DG: A study of beta-casein tertiary structure by intramolecular crosslinking and mass spectrometry. I Dairy Sci 2004, 87:3638-3647.

21. Sinz A: Chemical cross-linking and mass spectrometry to map threedimensional protein structures and protein-protein interactions. Mass Spectrom Rev 2006, 25:663-682.

22. Balasu MC, Spiridon LN, Miron S, Craescu CT, Scheidig AJ, Petrescu AJ, Szedlacsek SE: Interface analysis of the complex between ERK2 and PTPSL. PLoS One 2009, 4:e5432.

23. Studier FW: Protein production by auto-induction in high density shaking cultures. Protein Expr Purif 2005, 41:207-234.

24. Yang F, Roth MJ: Assembly and catalysis of concerted two-end integration events by Moloney murine leukemia virus integrase. J Virol 2001, 75:9561-9570.

25. Acevedo ML, Arbildua JJ, Monasterio O, Toledo H, Leon O: Role of the 207218 peptide region of Moloney murine leukemia virus integrase in enzyme catalysis. Arch Biochem Biophys 2010, 495:28-34.

26. Villanueva RA, Jonsson CB, Jones J, Georgiadis MM, Roth MJ: Differential multimerization of Moloney murine leukemia virus integrase purified under nondenaturing conditions. Virology 2003, 316:146-160.

27. Aloy P, Moont G, Gabb HA, Querol E, Aviles FX, Sternberg MJ: Modelling repressor proteins docking to DNA. Proteins 1998, 33:535-549.

doi:10.1186/1472-6807-13-14

Cite this article as: Henriquez et al.: Crosslinking and mass spectrometry suggest that the isolated NTD domain dimer of Moloney murine

leukemia virus integrase adopts a parallel arrangement in solution. $B M C$ Structural Biology 2013 13:14.

\section{Submit your next manuscript to BioMed Central and take full advantage of:}

- Convenient online submission

- Thorough peer review

- No space constraints or color figure charges

- Immediate publication on acceptance

- Inclusion in PubMed, CAS, Scopus and Google Scholar

- Research which is freely available for redistribution 